\title{
Effect of Source to Camera Distance and Count Rate on Intrinsic Uniformity of SPECT Gamma Camera
}

\author{
Sabrina Sarah1, Mahidul Haque Prodhann ${ }^{2}$, Kawsar Hamid ${ }^{2}$, Fazlul Huq ${ }^{2}$ \\ ${ }^{1}$ Department of Applied Physics, Electronics and Communication Engineering, University of Dhaka, Dhaka, \\ Bangladesh \\ ${ }^{2}$ Department of Nuclear Engineering, University of Dhaka, Dhaka, Bangladesh \\ Email: "mahiapecedu@gmail.com
}

Received 17 May 2015; accepted 7 June 2015; published 10 June 2015

Copyright @ 2015 by authors and Scientific Research Publishing Inc.

This work is licensed under the Creative Commons Attribution International License (CC BY).

http://creativecommons.org/licenses/by/4.0/

(c) (i) Open Access

\begin{abstract}
In this research, the excellent parameter for regular Quality Control (QC) testing of intrinsic uniformity for dual-head Single Photon Emission Computed Tomography (SPECT) gamma camera is determined. The integral and differential intrinsic uniformity tests for both Useful Field of View (UFOV) and Centre Field of View (CFOV) were done by insertion a point-source of ${ }^{99 \mathrm{~m} T c}$ in front of the detectors with detached collimators to measure the effect of source to camera distance and a count rate on intrinsic uniformity. The result reveals that the best intrinsic uniformity image is obtained at source-to-camera distance of $3 \mathrm{~m}$ and a count rate between 16 and $60 \mathrm{M}$.
\end{abstract}

\section{Keywords}

Quality Control (QC), Intrinsic Uniformity, Useful Field of View (UFOV), Centre Field of View (CFOV), Source to Camera Distance, Count Rate

\section{Introduction}

Gamma camera is a diagnostic instrument which presents an exquisite genus of imaging. It has developed out of the necessity in nuclear medical imaging to view and analyze images of the anthropoid body or the distribution of physically injected, inhaled, or ingested radionuclides radiating gamma rays [1]. In the arrangement for measuring the value of intrinsic uniformity of a gamma camera, the gamma ray spectrometry system is very essential.

Camera acceptance and the quality control test for a gamma camera system do not have any general agree-

"Corresponding author.

How to cite this paper: Sarah, S., Prodhan, M.H., Hamid, K. and Huq, F. (2015) Effect of Source to Camera Distance and Count Rate on Intrinsic Uniformity of SPECT Gamma Camera. Open Journal of Medical Imaging, 5, 78-84.

http://dx.doi.org/10.4236/ojmi.2015.52012 
ment [2] [3]. Many authors have proposed various protocols for carrying out QC tests for intrinsic uniformity [4]-[9]. According to National Electrical Manufacture Association (NEMA) [4] and International Atomic Energy Agency (IAEA) [5], the evaluation of detector non-uniformity is the most prevalent practice in present day quality control procedures of gamma camera. Before using gamma camera, day-to-day evaluation and judgment of flood-field uniformity are mandatory for patient testing [10] [11]. Any non-uniformity must be rejected and resolved before patient testing to diminish artifacts and false-positive or false-negative patient consequences. We favor intrinsic uniformity testing because a ${ }^{99 \mathrm{~m}} \mathrm{Tc}$ point source is freely available.

The majority of imaging in general nuclear medicine is performed with the gamma camera. Scintillation occurs when $\gamma$ photons emitted from the source or patient interacts with the sodium iodide crystal to produce light. The primary components of the scintillation camera include the collimator, scintillation crystal, photomultiplier tube, positioning logic network, pulse height analyzer, and display [12].

Two types of uniformity parameters are considered in SPECT imaging. Among them, the Integral Uniformity $(I U)$ is calculated as [13] [14],

$$
I U(\%)= \pm 100 \% \times \frac{\text { Max }- \text { Min }}{M a x+\operatorname{Min}}
$$

The maximum and the minimum pixel counts are found from the smoothed data. On the other hand, the Differential Uniformity $(D U)$ is calculated as [15],

$$
D U(\%)= \pm 100 \% \times \frac{\text { High }- \text { Low }}{\text { High }+ \text { Low }}
$$

We performed quality test in accordance to intrinsic uniformity for SPECT gamma camera [11]. The main purpose of this current research work is to determine the best parameters for daily quality control testing of intrinsic uniformity for dual head SPECT gamma camera from Siemens E. Cam signature series, Germany, installed at Institute of Nuclear Medicine and Allied Sciences (INMAS), Dhaka Medical College Hospital (DMCH), Dhaka. The integral and differential intrinsic uniformity test for both useful field of view (UFOV) and central field of view (CFOV) was done by placing a point source of ${ }^{99 \mathrm{~m}} \mathrm{Tc}$ in front of the detectors with removed collimators to measure the effect of source to camera distance and count rate on intrinsic uniformity. The intrinsic uniformity of the system is measured for the CFOV and UFOV [13]. The measured values are compared with the specification. The effects of source to camera distance and count rate have been investigated using intrinsic uniformity to assure quality control of SPECT gamma camera.

\section{Methodology}

\subsection{Source Materials}

${ }^{99 \mathrm{~m}} \mathrm{Tc}$ radionuclide was used to measure intrinsic uniformity in this research work. The gamma camera used in this research was a dual head fickle angle system, model E. Cam series, manufactured by Siemens (Model No. 7823946).

\subsection{Experimental Procedure and Data Acquisition System}

The collimator has been detached from the camera. The camera has been set with its face vertical to the floor. Source container has been settled on the gantry arm facing the center of detectors with wide-ranging detachment. Camera apparent and the room have been prepared to confirm that there is no contagion. Then, later eliminating all existing sources from the room, the background radiation of the room has been carefully measured using the $\mathrm{NaI}$ (TI) crystal of the gamma camera, which was 140 countper second. Activity of a ${ }^{99 \mathrm{~m}} \mathrm{Tc}$ source in a syringe has been measured in the dose calibrator afterward sex changing the needle.

The linearity of the dose calibrator in the range of $3.69-1799 \mathrm{MBq}$ was $<5 \%$. We varied the source activity between $10 \mathrm{MBq}$ and $240 \mathrm{MBq}$ to determine the effect of source activity on intrinsic uniformity. The volume of $95 \mathrm{MBq}$ point sources has been varied by adding $0.9 \%$ sodium chloride to the syringe to determine the effect of the point source volume on intrinsic uniformity. The point source has been carefully ranged with the center of the camera. The ${ }^{99 \mathrm{~m}} \mathrm{Tc}$ gamma spectrum has been attained and a $15 \%$ window width around the $140 \mathrm{keV}$ photopeak has been set. NEMA and IAEA approach for the measurement of intrinsic uniformity has been followed. The intrinsic flood-field image was obtained. The intrinsic uniformity of the SPECT camera i.e. Differential Un- 
iformity $(D U) \&$ Integral Uniformity $(I U)$ has been determined using Inter View and medical software where the extreme and least pixel values were determined. Figure 1 shows the schematic picture of SPECT gamma camera and detached collimator.

\section{Results and Analysis}

Table 1 and Table 2 show how the intrinsic uniformity varies with source to camera distance and count rate for detectors 1 and 2 with respect to both UFOV and CFOV.

Figure 2 and Figure 3 show the integral and differential intrinsic uniformity of Detector- 1 and Figure 4 and Figure 5 show the integral and differential intrinsic uniformity of Detector-2 respectively of the scheme versus the source to camera distance where the counting rate for acquiring the flood image was kept in the range of 50 $60 \mathrm{kcps}$ and the number of acquired counts for each flood image was $16 \mathrm{M}$. From the figure we found that both of the integral and differential intrinsic uniformity of the scheme enriched with increasing point source to camera distance. In our research 3.0 meter was the maximum distance.

Figure 6 and Figure 7 show the effect of the number of acquired counts on intrinsic uniformity of Detector-1 and Figure 8 and Figure 9 show the effect of the number of acquired counts on intrinsic uniformity of Detector-2 respectively of the scheme when $95 \mathrm{MBq}$ point source was used for all flood-field images, the intrinsic flood-field uniformity enhanced as the number of acquired counts for the flood-field image improved. The error bars on the figure shows the statistical variation. We demonstrated that by increasing the number of acquired counts (elongated stage to acquire the flood image), in both cases the differential and integral intrinsic uniformity for the UFOV and the CFOV improved because there were fewer statistical fluctuations. However, the incremental gain in intrinsic uniformity from 16 to $60 \mathrm{M}$ was least.

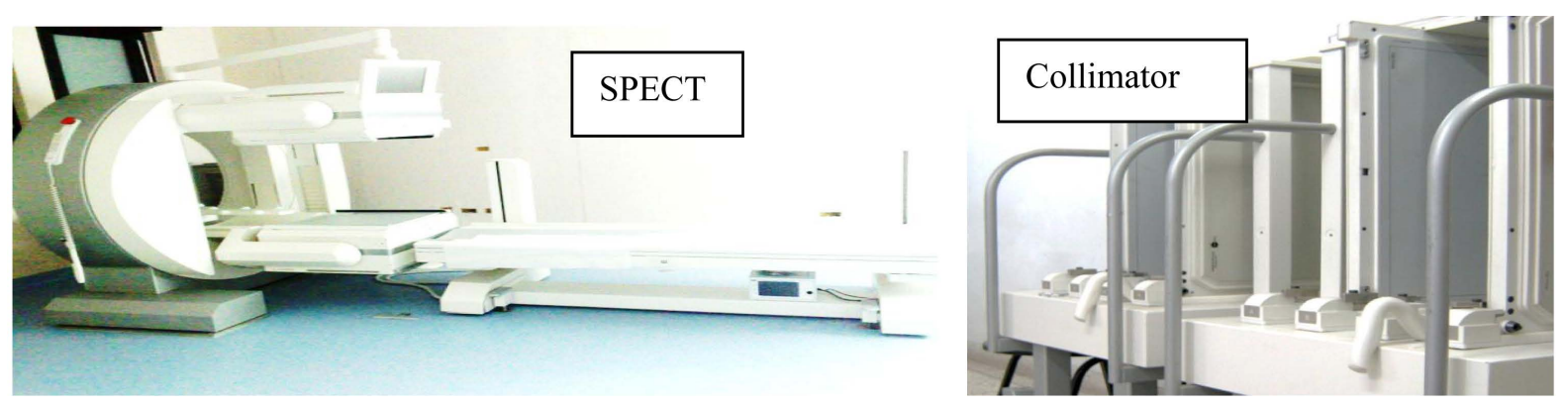

Figure 1. SPECT gamma camera and detached collimator.

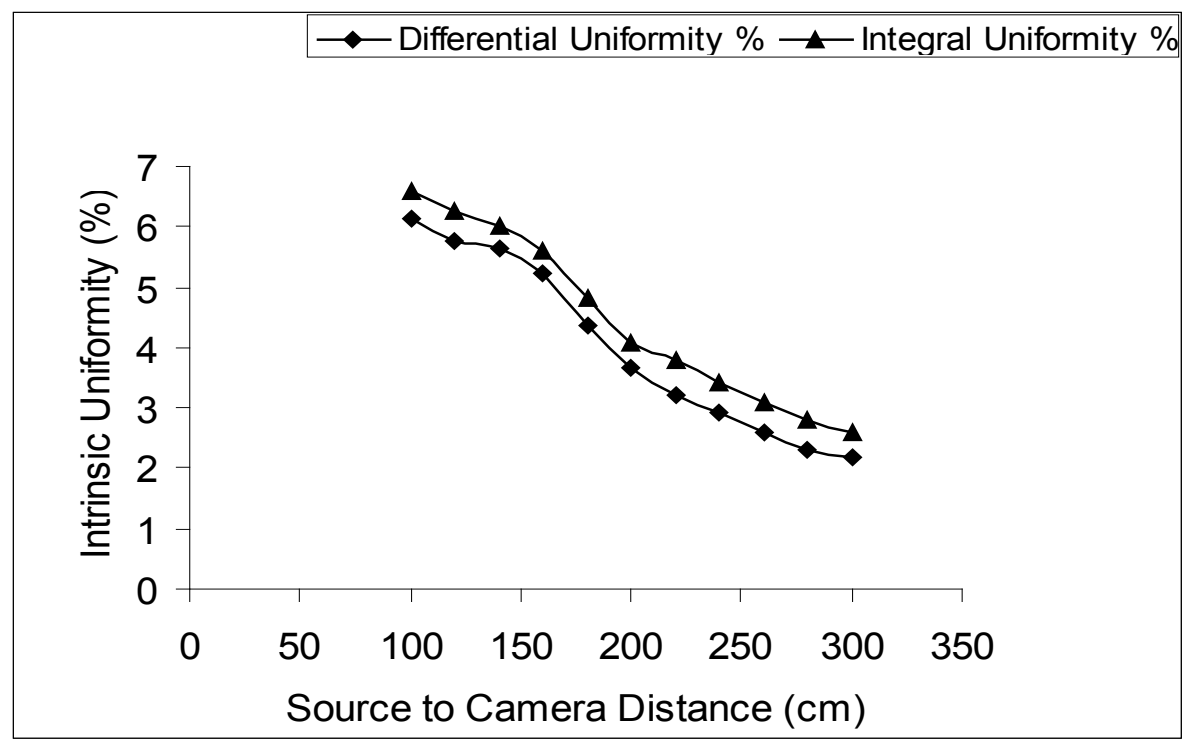

Figure 2. Intrinsic uniformity vs. source to camera distance in UFOV (Detector-1). 


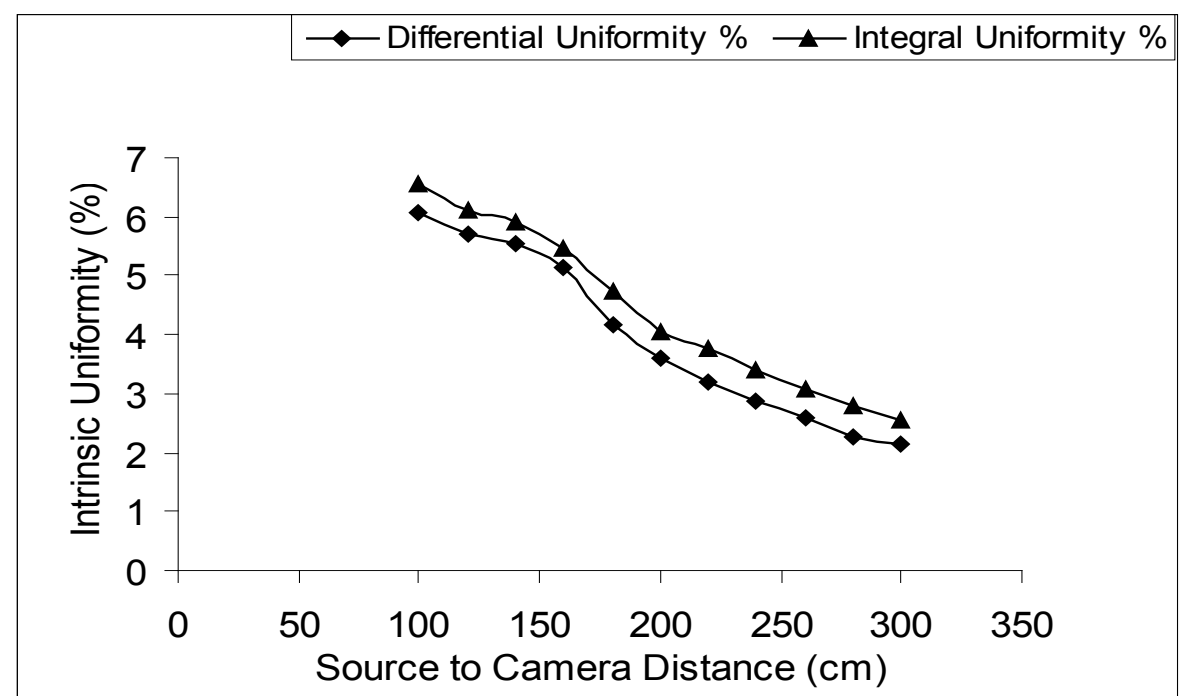

Figure 3. Intrinsic uniformity vs. source to camera distance in CFOV (Detectot-1).

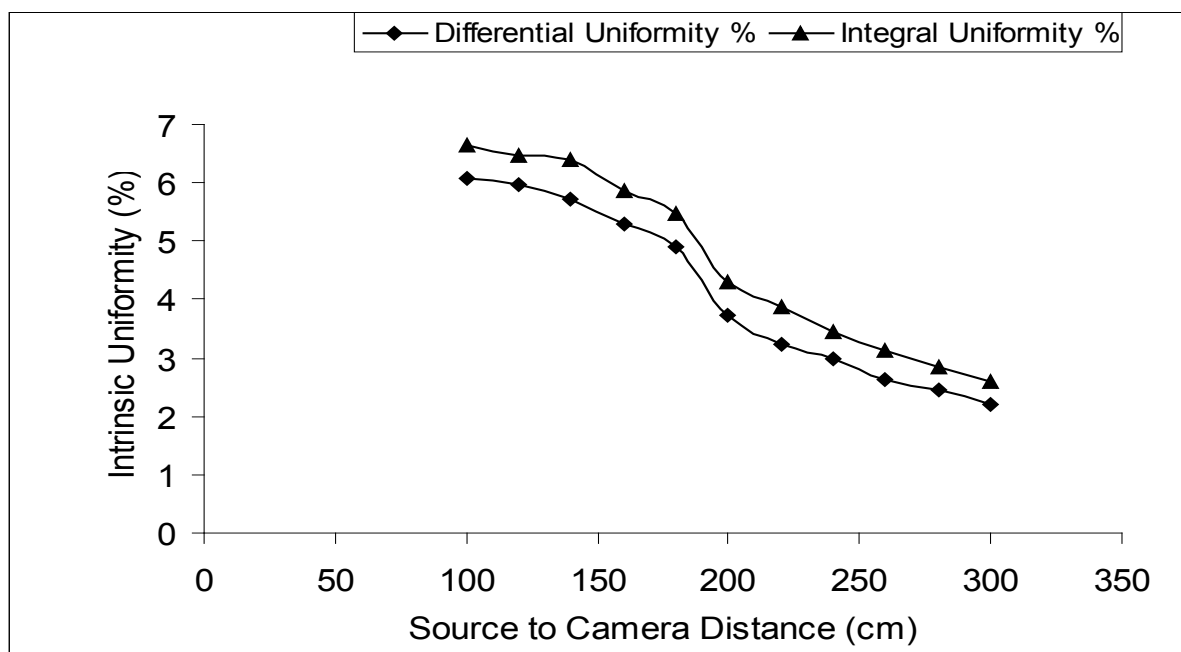

Figure 4. Intrinsic uniformity vs. source to camera distance in UFOV (Detector-2).

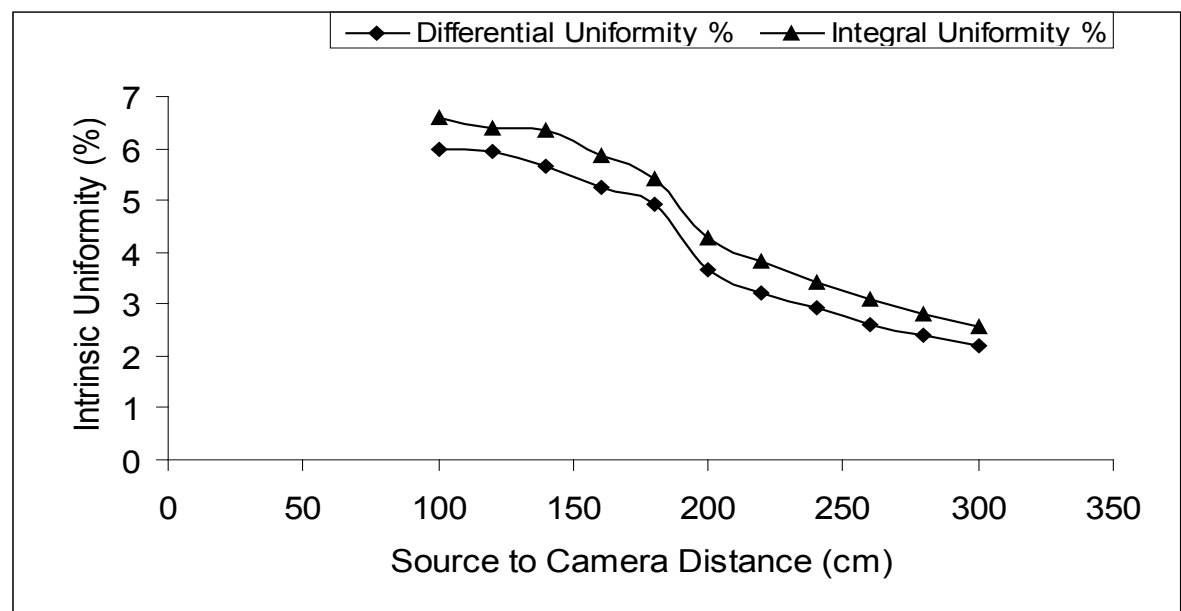

Figure 5. Intrinsic uniformity vs. source to camera distance in CFOV (Detector-2). 


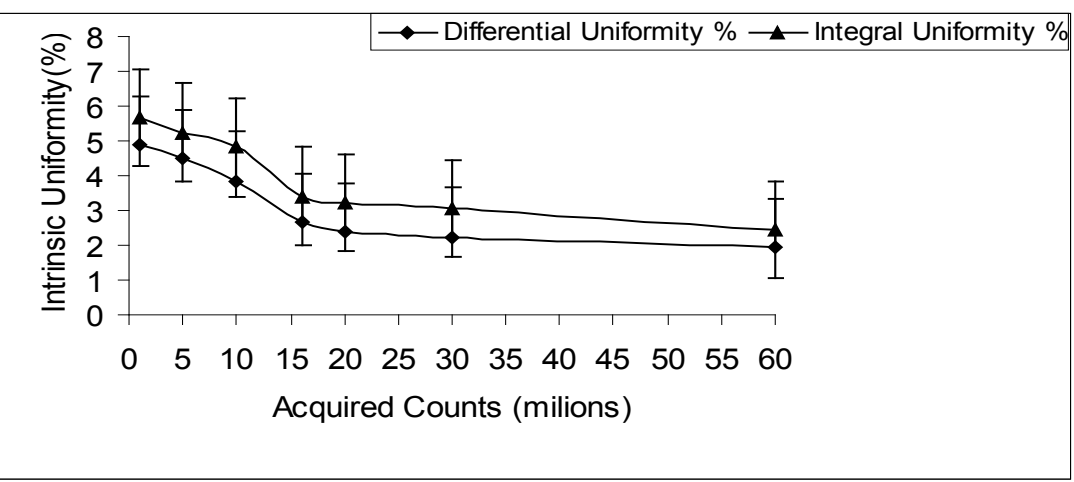

Figure 6. Intrinsic uniformity vs. number of acquired counts in UFOV (Detector-1).

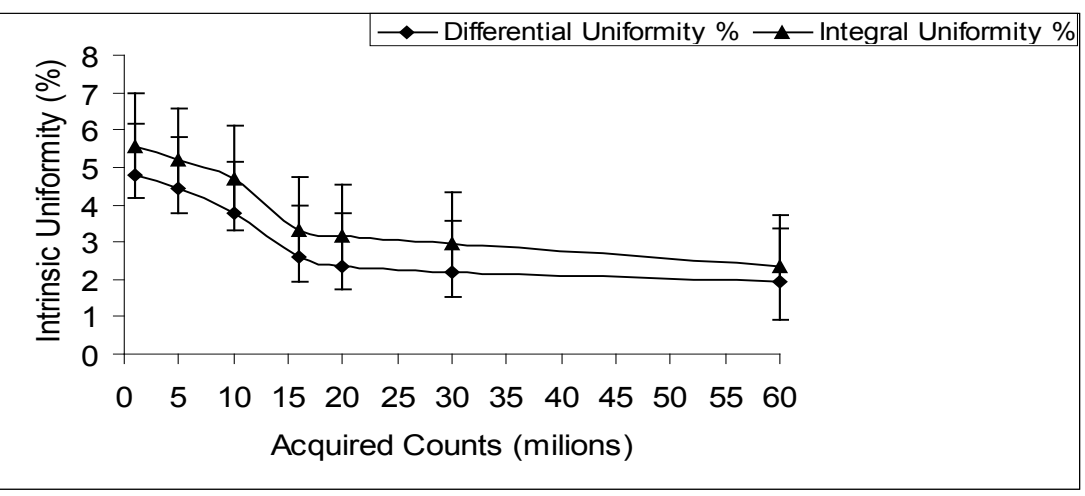

Figure 7. Intrinsic uniformity vs. number of acquired counts in CFOV (Detector-1).

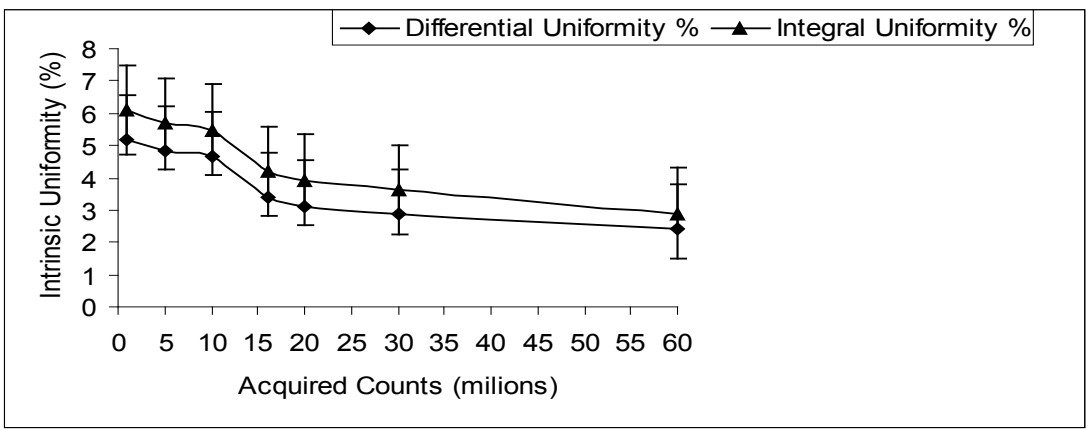

Figure 8. Intrinsic uniformity vs. number of acquired counts in UFOV (Detector-2).

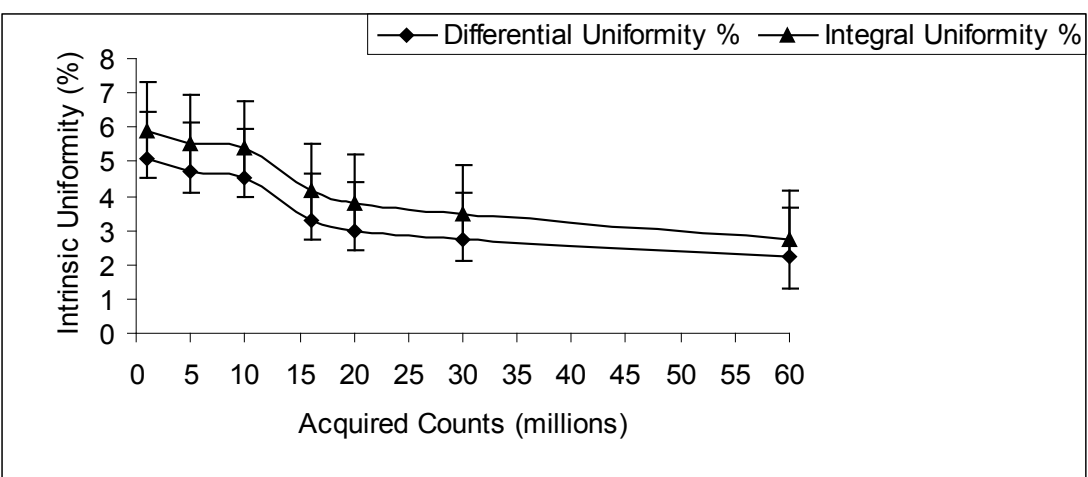

Figure 9. Intrinsic uniformity vs. number of acquired counts in CFOV (Detector-2). 
Table 1. Intrinsic uniformity vs. source to camera distance.

\begin{tabular}{|c|c|c|c|c|c|c|c|c|}
\hline \multirow{3}{*}{$\begin{array}{c}\text { Source to } \\
\text { Camera } \\
\text { Distance (cm) }\end{array}$} & \multicolumn{4}{|c|}{ Detector-1 } & \multicolumn{4}{|c|}{ Detector-2 } \\
\hline & \multicolumn{2}{|c|}{ UFOV (\%) } & \multicolumn{2}{|c|}{ CFOV (\%) } & \multicolumn{2}{|c|}{ UFOV (\%) } & \multicolumn{2}{|c|}{ CFOV (\%) } \\
\hline & $D U$ & $I U$ & $D U$ & $I U$ & $D U$ & $I U$ & $D U$ & $I U$ \\
\hline 100 & 6.12 & 6.66 & 6.06 & 6.56 & 6.06 & 6.66 & 6.0 & 6.6 \\
\hline 120 & 5.78 & 6.25 & 5.7 & 6.11 & 5.97 & 6.45 & 5.93 & 6.39 \\
\hline 140 & 5.63 & 6.01 & 5.54 & 5.92 & 5.71 & 6.38 & 5.66 & 6.33 \\
\hline 160 & 5.22 & 5.62 & 5.14 & 5.47 & 5.31 & 5.87 & 5.24 & 5.87 \\
\hline 180 & 4.38 & 4.8 & 4.18 & 4.72 & 4.89 & 5.47 & 4.94 & 5.43 \\
\hline 200 & 3.65 & 4.09 & 3.61 & 4.05 & 3.72 & 4.3 & 3.67 & 4.26 \\
\hline 220 & 3.2 & 3.77 & 3.19 & 3.76 & 3.25 & 3.88 & 3.21 & 3.84 \\
\hline 240 & 2.93 & 3.42 & 2.89 & 3.39 & 2.98 & 3.45 & 2.92 & 3.4 \\
\hline 260 & 2.61 & 3.09 & 2.58 & 3.09 & 2.64 & 3.14 & 2.6 & 3.09 \\
\hline 280 & 2.3 & 2.8 & 2.28 & 2.79 & 2.44 & 2.84 & 2.39 & 2.79 \\
\hline 300 & 2.19 & 2.58 & 2.16 & 2.56 & 2.22 & 2.61 & 2.18 & 2.57 \\
\hline
\end{tabular}

Note: $\mathrm{UFOV}=$ Useful Field Of View $\mathrm{CFOV}=$ Centre Field Of View; $D U=$ Differential Uniformity; $I U=$ Integral Uniformity.

Table 2. Intrinsic uniformity vs number of acquired counts.

\begin{tabular}{|c|c|c|c|c|c|c|c|c|}
\hline \multirow{3}{*}{$\begin{array}{l}\text { Number of } \\
\text { Acquired } \\
\text { Counts } \\
\text { (Millions) }\end{array}$} & \multicolumn{4}{|c|}{ Detector-1 } & \multicolumn{4}{|c|}{ Detector-2 } \\
\hline & \multicolumn{2}{|c|}{ UFOV (\%) } & \multicolumn{2}{|c|}{ CFOV (\%) } & \multicolumn{2}{|c|}{ UFOV (\%) } & \multicolumn{2}{|c|}{ CFOV (\%) } \\
\hline & $D U$ & $I U$ & $D U$ & $I U$ & $D U$ & $I U$ & $D U$ & $I U$ \\
\hline 1 & 4.87 & 5.67 & 4.78 & 5.56 & 5.16 & 6.1 & 5.08 & 5.92 \\
\hline 5 & 4.49 & 5.24 & 4.43 & 5.18 & 4.83 & 5.67 & 4.72 & 5.52 \\
\hline 10 & 3.86 & 4.81 & 3.75 & 4.69 & 4.64 & 5.48 & 4.55 & 5.37 \\
\hline 16 & 2.65 & 3.41 & 2.6 & 3.33 & 3.37 & 4.21 & 3.28 & 4.13 \\
\hline 20 & 2.39 & 3.22 & 2.36 & 3.14 & 3.12 & 3.93 & 3.0 & 3.8 \\
\hline 30 & 2.25 & 3.04 & 2.19 & 2.95 & 2.85 & 3.62 & 2.71 & 3.49 \\
\hline 60 & 1.96 & 2.44 & 1.96 & 2.32 & 2.41 & 2.84 & 2.24 & 2.73 \\
\hline
\end{tabular}

Note: $\mathrm{UFOV}=$ Useful Field Of View; $\mathrm{CFOV}=$ Centre Field Of View; $D U=$ Differential Uniformity; $I U=$ Integral Uniformity.

\section{Conclusion}

From this research, the QC parameters in accordance with intrinsic uniformity, the results ensemble the fact that the intrinsic uniformity is apt as long as it is maintained to the minimum level i.e. the lower the intrinsic uniformity is, the better the imaging and diagnosis are. The result confirms that the best intrinsic uniformity image is attained at source to camera distance of $3 \mathrm{~m}$ and a count rate between 16 and $60 \mathrm{M}$. If one can maintain this result in case of SPECT gamma camera imaging, then best images will be investigated to perform better diagnosis.

\section{Acknowledgements}

The authors are grateful to Mr. Md. Sanowar Hossain, Professor and Director, Institute of Nuclear Medicine \& Allied Sciences, Bangladesh Atomic Energy Commission, Dhaka, Bangladesh and Mr. Md. Selim Reja, Chief Scientific Officer (CSO), Institute of Nuclear Medicine \& Allied Sciences, Bangladesh Atomic Energy Commission (BAEC), Dhaka, Bangladesh, for allowing and continuing the research and helping throughout the research activity. 


\section{References}

[1] Paris, P., Hine, G.L. and Adams, R. (1981) BRH Test Pattern for the Evaluation of Gamma-Camera Performance. The Journal of Nuclear Medicine, 22, 468-470.

[2] Lewellen, T.K. and Grahan, M.M. (1981)A Low-Contrast Phantom for Daily Quality Control. The Journal of Nuclear Medicine, 22, 279-282.

[3] Hasegawa, B.H., Kirch, D.L., Lefree, M.T., Vogel, R.A., Steele, P.P. and Hendee, W.R. (1981) Quality Control of Scintillation Cameras Using a Minicomputer. The Journal of Nuclear Medicine, 22, 1075-1080.

[4] National Electrical Manufacturers Association (2001) NEMA NU 1-2001: Performance Measurements of Scintillation Cameras. http://www.nema.org/stds/nu1.cfm

[5] IAEA-TECDOC-602 (1991) Quality Control of Nuclear Medicine Instruments. http://www-pub.iaea.org/MTCD/Publications/PDF/te_602_web.pdf

[6] International Electrotechnical Commission IEC Standard 61675-2 (2005) Radionuclide Imaging Devices - Characteristics and Test Conditions_-Part 2: Single Photon Emission Computed Tomographs. http://webstore.iec.ch/preview/info iec61675-2\%7Bed1.1\%7Den.pdf

[7] O'Connor, M.K., Clinic, M. and Rochester, M.N. (1999) Quality Control of Scintillation Cameras (Planar and SPECT). http://www.aapm.org/meetings/99AM/pdf/2741-51264.pdf

[8] American Association of Physicists in Medicine-Nuclear Medicine Committee (1980) Scintillation Camera Acceptance Testing and Performance Evaluation. AAPM Report No. 6. American Institute of Physics, AIP Publishing, One Physics Ellipse College Park, MD 20740 (301) 209-3100. https://www.aapm.org/pubs/reports/rpt_06.pdf

[9] Zobly, S.M.S. and Osman, A.O. (2010) Effect of Different Parameters on Intrinsic Uniformity Test for MEDISO Single-Head Gamma Camera. Journals of University of Gezira, 5, 1-9.

[10] Bushberg, J.T., Seibert, J.A., Leidholdt, E.M. and Boone, J.M. (2002) Essential Physics of Medical Imaging. 2nd Edition, Lippincott Williams \& Wilkins, Philadelphia.

[11] Ejeh, J.E., Adedapo, K.S., Akinlade, B.I. and Osifo, B.O.A. (2011) Gamma Camera Intrinsic Uniformity in an Unstable Power Supply Environment. Hellenic Journal of Nuclear Medicine, 14.

[12] Anger, H.O. (1964) Scintillation Camera with Multichannel Collimators. The Journal of Nuclear Medicine, 5, $515-531$.

[13] Cherry, S.R., Sorenson, J.A. and Phelps, M.E. (2012) Physics in Nuclear Medicine. 4th Edition, Elsevier Inc., Philadelphia.

[14] Abdelhalim, M.A.K., Rizk, R.A.M., Farag, H.I. and Reda, S.M. (2009) Effect of Energy Window Width on Planer and SPECT Image Uniformity. Journal of King Saud University-Science, 21, 145-150. http://dx.doi.org/10.1016/j.jksus.2009.06.001

[15] Liu, Y.H., Sinusas, A.J., DeMan, P., Zaret, B.L. and Wackers, F.J. (1999) Quantification of SPECT Myocardial Perfusion Images: Methodology and Validation of the Yale_CQ Method. Journal of Nuclear Cardiology, 6, 190-204. http://dx.doi.org/10.1016/S1071-3581(99)90080-6 